\title{
浅探建筑工程管理中的信息化管理应用
}

\author{
袁绍雷 \\ 新疆红星建设工程(集团)有限公司 \\ DOI:10.18686/bd.v2i5.1389
}

[摘 要] 建筑工程在信息科学技术繁㭉发展中取得更大的发展, 当前建筑工程管理模式已经慢慢在转型, 从原来的人工管 理转向信息化管理。

[关键词] 建筑; 工程管理; 信息化管理; 应用

\section{1 概述建筑工程信息化管理的意义}

在传统的建筑工程管理模式中, 工程项目上各种信息 的存储主要是基于表格或单据等纸面形式, 信息的加工和 整理完全由大量的手工计算来完成, 信息的交流则绝大部 分依赖于人与人之间的手工传递甚至口头传递, 信息的检 索则完全依赖于对文档资料的翻阅和查看。信息从它的产 生、整理、加工、传递到检索和利用,都在以一种较为缓慢的 速度在运动, 这容易影响信息作用的及时发挥而造成项目 管理工作中的失误。

近年来, 一些实力雄厚的企业率先应用先进的计算机 技术来辅助项目管理工作。例如,使用 PKPM 概预算软件编 制施工概预算, 使用各种智能网络计划编制与管理软件安 排施工进度,用 AutoCAD 图形软件绘制竣工图纸等等, 用施 工资料软件编制工程技术、安全资料, 使项目管理工作的质 量和工作效率都有了显著改善。一方面,这说明在施工中应 用信息技术的必要性;另一方面,各参与者工作方式得到了 改善,减轻了工程技术人员的工作量,工程成本控制也得到 了进一步细化。但是工程项目的信息化管理,不仅仅意味着 在管理过程中使用计算机, 它还具有更广泛更深刻的内涵。 首先, 对管理过程中需要处理的信息进行高效地采集、加 工、传递和实时共享,减少部门之间对信息处理的重复工作, 为项目管理服务、为项目决策提供可靠的依据; 其次, 它使 监督检查等控制及信息反馈变得更为及时有效, 使项目施 工活动以及项目管理活动流程的组织更加科学化, 利用对 工程进度、成本、合同、安全、质量、协调等信息的控制和管 理,有利于项目管理层的管理。

\section{2 分析当前建筑工程管理信息化现状}

我国的建筑工程管理是在建筑工程中运用高科技信息 化技术, 提供有效数据交流共享平台, 对每个环节全方位进 行信息资源的整合,开发出存储信息的数据库,有效的提高 建筑工程管理的效率。信息不仅是一项技术, 更是组织形 态、管理方式以及管理思想的变革,近几十年来,信息在建筑 工程管理的各个领域已经开始飞速发展。对于目前来说,我 国建筑工程管理中的信息化还处于起步阶段, 信息化应用 水平较低, 很多建筑单位对于工程的信息化管理不够重视, 建筑工程的管理人员对于信息化技术的认识不足, 其认识
和观念有待转变。此外,目前为建筑工程开发的一些信息化 软件操作复杂, 使用起来也不方便, 这是导致建筑工程的人 员参与度较低, 从而致使我国建筑工程管理的信息化发展 缓慢, 直接影响到建筑工程管理的效果和质量。所以, 我国当 前建筑工程管理信息化现状急需改变。

\section{3 分析建筑工程管理中的信息化存在的不足}

3.1 仍采用传统的建筑工程管理模式

传统的建筑工程管理体制、运行程序较难适应于信息 化需求, 信息化的迅速发展要求企业提供统一的管理模式, 而部分企业在原有的管理体制和运行程序没有很大改变, 在很大程度上阻碍了信息化的发展。另外,有的企业只在单 方面要求信息化满足现有的建筑工程管理模式, 使得信息 化的发展偏离了应有方向, 没有达到发展信息化与企业管 理相结合。

\section{2 缺乏研究开发信息化的能力}

建筑工程管理中信息化的开发是投人巨大的任务,除 了需要雄厚的资金支持,还需要技术上的支持,对于技术人 员的需求也非常高,因此,对于一般的企业,信息化建设的资 金见效慢、投人大以及建设周期长, 通常是因为没有足够的 资源支持信息化的开发能力。同时由于信息化的研发需要 较大的资金投人, 因此即使委托专业单位开发或者从外部 购买也需要较高的成本, 而这样的投人对于一般企业来说 很难收回, 这是阻碍建筑工程管理中的信息化发展的重要 因素之一。

\section{3 建筑工程管理中缺乏信息化统一标准}

目前, 我国没有出台建筑工程管理中的信息化统一标 准,行业内部的信息化无法进行有效信息交流,资源得不到 优化、整合,因此建筑企业工程管理中信息化缺乏信息化统 一标准。在建筑企业内部, 由于缺乏建筑工程管理中统一信 息化标准, 不同软件信息无法在企业不同部门间共享信息 资源,各环节信息数据无法进行有效交流、相互关联,很多基 础工作在工程管理的不同环节重复进行着, 难以得到有效 控制数据的质量。

\section{4 建筑工程信息化存在误区}

建筑工程管理过程中存在信息化误区就是只要有了计 算机、局域网就实现了企业的信息化。大部分建筑工程主 
方、设计施工方以及监理方的信息交换仍然采用纸介质来 进行交流,而没有因为推进信息化而有所改变。作为建筑工 程管理信息化的根本前提就是必须数字化, 信息化交换必 须是在电子介质或网络上来进行交流。而现阶段建筑企业 信息化充其量只不过是建筑工程管理的工具, 并没有带来 任何工作模式的改变。

\section{4 分析我国建筑工程管理信息化管理的有效措施}

4.1 健全建筑工程的信息化平台

企业的项目部应该有效管理局域网，互联网等信息平 台,使信息的交流更加方便安全,降低企业项目部中存在的 风险,实现建筑工程管理服务的完善。积极发展计算机技术, 将计算机技术应用到建筑施工管理上去, 使决策等朝着时 效性发展,使规划朝着科学性进步。建立健全的信息化管理, 使得信息朝着规范化方向发展。创建出以数据为中心的工 作流程,使得传统的管理朝信息化发展,充分发挥数据在信 息化中的作用,避免出现重复或交叉的工作。工程项目信息 化在考虑不同参与方需求的基础上, 建立出一个对施工现 场管理,项目远程监控,项目多方协作,企业知识和情报管理 和警报等多方面,实现资源利用的最大化。

4.2 加强管理信息化工作建设

分层推进,将基础性工作妥善完成。信息技术初步应用 的过程中发挥出来的作用是战术层面的，但是在信息技术 应用深化水平逐渐提升的情况下, 就会逐渐形成一定的战 略性影响,从充当自动化工具以及信息沟通措施,一直到对 企业运营模式和具体组织结构造成影响, 这其实是一个比 较漫长的过程。信息系统发展速度和两种因素之间有较为 密切的相互关系,第一是会随着企业的发展而得到发展。信 息系统得到的发展, 又可以在企业日后发展的过程中发挥 出来促进性作用。从而也就可以在企业当中形成一种良性 循环。第二是会随着员工计算机应用水平提升而提升,教育 培训工作应当被放置在较为重要的地位上, 让员工可以对 数字化工具形成深人的认识, 以便于可以将学习积极性和 主动性激发出来,最终让员工信息技术水平大幅度提升。

4.3 创建以数据为中心的建筑工程模式

信息化管理过程是项目各参与方之间流动、传递信息 的过程,传统的管理模式,信息都是以书面通知、电话等方式 缓慢和重复进行, 任意环节信息的获得在有关部门的协作
下才能顺利完成,一定程度上信息传递的及时性有所降低。 为了避免出现建筑行业信息化的重复工作, 加快信息数据 的传递速度,从而保证信息传递质量。建筑工程管理的信息 化系统必须以数据为中心, 项目参与者工作职责、内容以数 据为依据,实现一次输人、多次使用的信息化项目,只要完成 自己的工作,信息化系统将实现建筑企业业务的自动流动。

4.4 建筑企业在观念上做到实事求是, 与时俱进

在推进企业信息化的中. 不同建筑行业必须从自己的 实际情况需求出发,确定本企业的信息化,不可盲目照搬。目 前,有的建筑企业建立了局域网和管理信息化系统,实现了 企业信息化管理。大部分企业还只限于使用工程招投标系 统、财务管理以信息化为支撑的单项办公应用软件,信息化 的总体水平较低。今后,企业一方面要继续完善已有的信息 化工作成果,使用数字化,同时结合公司新发展战略,展开具 有前瞻性信息化基管理工作。另一方面能够充分享受政府 和社会的公共资源, 参与社会电子认证体系和信用系统采 用网络公共服务数字化系统。

\section{5 结束语}

总之,对于建筑行业来说,将其管理模式信息化是其改 革创新以提高建筑工程管理生命力的重要手段, 同时也是 全球信息化的必然要求,也是建筑企业信息化发展趋势。遵 循一定的研发步骤是开发高质量建筑施工项目信息化系统 的根本保障,对建筑施工项目实行信息化管理,通过实现企 业的信息化共享,提供一个良好的协同工作环境,进而提高 建筑企业的整体经济效益和工作效率。因此,不断加强完善 我国建筑工程管理信息化是建筑产业不断发展的必然要 求。我国的建筑行业也必将会完善自身的现状和存在问题, 不断提高自身的信息化管理水平, 从而带来整个建筑行业 的迅速发展。

\section{参考文献:}

[1]邩建平.浅析信息化背景下的建筑工程管理 [J]. 建 材与装饰,2017(50):297-298.

[2]尚亚军.信息化背景下的建筑工程管理分析 [J]. 工 程技术研究,2017(11):159-160.

[3]高龙龙.工程管理信息化应用模式研究 [J]. 中国集 体经济,2017(01):45-46. 